\title{
Uso y aplicación de la geología y geomorfología en la evaluación ambiental de proyectos en el borde costero de Santa Catarina, Brasil: un estudio de caso aplicado
}

\author{
Ricardo Augusto Lengler Franchini ${ }^{1,2}$, rickfranchini@hotmail.com; Rafael Mastracusa \\ de Oliveira ${ }^{1}$; Fernando Comerlato Scottá ${ }^{1}$; Flávia Cristina Farina ${ }^{2}$; Tatiana Silva da \\ Silva $^{3}$; Maria Luiza Câmara da Rosa ${ }^{3}$; Ricardo Norberto Ayup-Zouain 1,2, 3,4 \\ RESUMEN
}

La investigación expone la importancia de la información geológica y geomorfológica realizada para el estudio ambiental de un terminal pesquero en el Municipio de Passo de Torres, Estado de Santa CatarinaSC, Brasil. Es un trabajo de investigación aplicada que permitió identificar seis unidades geomorfológicas, la planicie y terraza lacustre, el paleo campo de dunas, los cordones litorales, las dunas regresivas y los paleocanales del río Mampituba. Asociadas a estas formas se identificaron unidades geológicas, tales como depósitos eólicos, de playas y aluviales holocénicos, depósitos de turbas del Holoceno, depósitos de playas y eólicos pleistocenos y basamento de la Serra Geral. La información de geomorfología y geología aplicada a la evaluación ambiental fue respaldada con bases de datos de COMPANHIA DE PESQUISAS DE RECURSOS MINERAIS (CPRM) y del INSTITUTO BRASILEÑO DE GEOGRAFÍA Y ESTADÍSTICA (IBGE), además de la validación del trabajo de terreno. A través del uso de técnicas de sensores remotos y la integración de datos con herramientas SIG, se realizó la identificación de las unidades descritas y la cartografía asociada en diferentes escalas, 1:50.000 para el municipio y 1:2.000 para el área del terminal pesquero a ser evaluado.

Palabras clave: Geología y geomorfología; planicie litoral; SIG.

\section{Use and application of geology and geomorphology for the environmental assessment of projects on the coast of Santa Catarina, Brazil: applied study case}

\begin{abstract}
Information about geology and geomorphological evolution of an area are recognition parts of their spatial dynamics and climate evolution. The study aims at presenting the geological and geomorphological survey for terminal public fishing environmental licensing in Passo de Torres city, located in the coastal plain, southern state of Santa Catarina - SC, Brazil. This study was based on official work related to geology and geomorphology of the region, provided respectively by the Company of Mineral Resources Research (CPRM) and the Brazilian Institute of Geography and Statistics (IBGE), associated with field surveys to corroborate with vectors forming the digital database. Six geomorphological units (plain lagoon, lagoon terrace, paleo dune, beach ridges, regressive lields dunes, Mampituba river paleochannel) and six geological units were identified (Holocene eolian deposits, Holocene beach deposits, Holocene alluvial deposits, Holocene peatland, Pleistocene beach deposits and eolian deposits, Serra Geral basement). Through the utilization of Remote Sensing techniques and data integration in GIS it was possible to identify and describe them in detail, representing them in maps at different scales (1:50,000 in city area and 1:2,000 in the fishing area) in order to assist the preparation of the Coastal Environmental Impact Report of the Public fishing terminal in Passo de Torres city, SC.
\end{abstract}

Keywords: geology and geomorphology; coastal plain; GIS.

Recibido el 9 de junio de 2014, aceptado el 10 de diciembre de 2014.

\footnotetext{
Laboratório de Modelagem de Bacias, Universidade Federal do Rio Grande do Sul. Avenida Bento Gonçalves, 9500. Porto Alegre, RS, Brasil.

2 Programa de Pós-Graduação em Geociências - PPG-GEO, Instituto Geociências - Universidade Federal do Rio Grande do Sul.

3 Departamento de Geodésia, Universidade Federal do Rio Grande do Sul.

4 Centro de Estudos de Geologia Costeira e Oceânica - CECO, Instituto Geociências - Universidade Federal do Rio Grande do Sul.
} 


\section{INTRODUCCIÓN}

Se integra el diagnóstico ambiental del proyecto Terminal Pesquero de Passo de Torres - SC, realizado entre el Ministerio Público Federal de Santa Catarina y la Universidad Federal do Rio Grande do Sul, para regular el área según normativas ambientales de resolución CONAMA $\mathrm{N}^{\circ} 303 / 2002$ y el código Ley Federal $\mathrm{N}^{\circ} 12.651 / 2012$, según las directrices legales propuestas por la FUNDACIÓN DE MEDIO AMBIENTE DE SANTA CATARINA y la legislación vigente en la ley de puertos (Ley Federal No 8.630/93).

La caracterización geológica y geomorfológica de esta investigación aplicada constituyen un valor adicional de información física y estructural que permite un mejor análisis de los componentes asociados a la dinámica del río Mampituba y su relación con la obra. Se realizan los estudios geológicos asociados a la definición del substrato del área (caracterización de las rocas y de los sedimentos), evolución geológica de la planicie costera, tanto como el análisis geomorfológico que permiten conocer la dinámica física del territorio. El municipio de Passo de Torres se encuentra en la costa sur del estado de Santa Catarina - Brasil, está situado al sur de la Laguna de Sombrío y al norte del municipio de Torres - RS (Fig. 1).

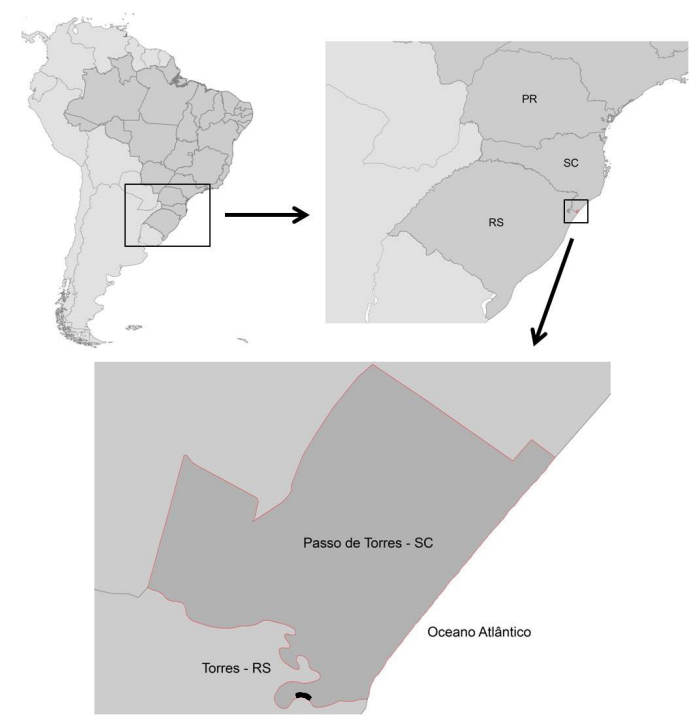

Fig. 1. Localización del área de estudio. Se destaca el área del proyecto a ser desarrollado, en las orillas del río Mampituba.

En el contexto de la evolución geológica del área de estudio, el municipio forma parte de una región bastante reciente (DIEHL \& HORN 1996), en donde la dinámica evolutiva de la zona costera se correlaciona con las descripciones de SUGUIO \& MARTIN (1978), asociadas a las variaciones de la costa debido a las fluctuaciones en el nivel del mar durante el Cuaternario. La región se caracteriza por una planicie costera bien desarrollada y consolidada por una secuencia de depósitos de barrera arenosa. En esta secuencia de depósitos de barreras arenosas, destacan los 
registros de la dinámica costera descritos por MARTIN et. al. (2006), remanentes de depósitos lacustres y de playa en un perfil de aproximadamente $25 \mathrm{~km}$ entre la costa y la vertiente de la escarpa de la unidad correspondiente a la provincia Geomorfológica del Planalto Sul-Brasileiro.

Según SILVA (2009), la región tiene como principal característica la presencia de depósitos lacustres y de playas asociados a los sistemas laguna-barrera pleistocénicos, semejantes a los que se encuentran en la planicie costera de Río Grande do Sul (VILLWOCK et. al. 1986; VILLWOCK \& TOMAZELLI 1995).

\section{MATERIALES Y MÉTODOS}

Para la elaboración de esta investigación aplicada fueron conjugados trabajos relacionados con la geomorfología y la geología de la región según bases de datos cartográficos proporcionados por la Compañía de Recursos Minerales de Investigación (CPRM) (2009) del Servicio Geológico de Brasil (SGB) y el Instituto Brasileño de Geografía y Estadística (IBGE), además de trabajos de campo para la validación de la información específica y cartográfica. De esta forma, el levantamiento fue realizado por etapas, fase de campo y de laboratorio SIG.

\section{Estudio de campo}

Se recolectaron coordenadas de terreno para la validación y corrección de la cartografía base utilizada para la producción de las cartasimágenes. Se utilizó GPS Garmin en una navegación de $5 \mathrm{~m}$ de precisión horizontal; se midieron coordenadas en las cimas de los cerros, bordes de lagunas, pantanos y bordes de las cimas de las barreras arenosas.

\section{Laboratorio SIG}

Se analizó la bibliografía correspondiente al marco geológico y geomorfológico asociado a la planicie costera del sur de Santa Catarina, realizando una revisión de la información presente en la base cartográfica del Servicio Geológico de Brasil (SGB). Para ello, se utilizó el software Arcgis $10 \AA$ para la corrección o la inserción de características no computadas en la base cartográfica, en un mosaico de imágenes satelitales. Para el montaje del mosaico fueron utilizadas tres imágenes pancromáticas de sensor SPOT, con fechas 02/08/2002, 27/08/2002 y $14 / 03 / 2003$, con una resolución espacial de $10 \mathrm{~m}$, georreferenciadas en el sistema de coordenadas SIRGAS 2000, zona 22 Sur, según lo sugerido por el Sistema Cartográfico Nacional (SCN). Después de cada paso del análisis y tratamiento de los datos recopilados y disponibles, se pasó a la etapa de la producción y la vectorización a través de herramientas SIG, que permitieron la elaboración de la cartografía de detalle.

\section{Geología}

La planicie costera del Estado de Santa Catarina presenta un patrón de distribución de facies y ambientes de depósito similar a lo descrito por VILLWOCK \& TOMAZELLI (1995) para la planicie costera de Río Grande do Sul, y el modelo evolutivo que se considera el estándar geológico del Holoceno para las costas del sur de Brasil. Es posible observar los patrones y las evidencias de las variaciones en el nivel relativo del mar durante los últimos 400.000 años, donde las elevaciones eustáticas (transgresiones marinas) y los períodos de rebajamientos eustáticos de nivel medio del mar (regresiones marinas), esculpieron las colinas remanentes, construyeron las facies de restinga (barreras y campos de dunas) y las planicies arenosas entre estos, correspondientes a antiguos niveles de playa. Esta variación del nivel del mar ocurrida durante el Cuaternario contribuyó a la configuración geomorfológica $\mathrm{y}$ sedimentaria de la planicie costera Sul do Brasil, modelando los sistemas de abanicos aluviales ya existentes y el surgimiento de las facies tipo laguna-barrera. Los procesos de variación del nivel del mar modelaron 
la provincia costera del sur de Brasil a través del lento re-trabajo de los sedimentos disponibles, generando las unidades geomorfológicas definidas como sistema de laguna barrera.

\section{Geomorfología}

Para un mejor conocimiento de la zona de interés, se realizó un estudio geomorfológico según información disponible en las fuentes bibliográficas. Las principales características morfológicas que se presentan en la costa sur de Santa Catarina fueron descritas por SILVA (2011), quien identificó las facies laguna-barrera desarrolladas durante el Cuaternario Superior. El autor presenta evidencias que permiten señalar que el área del municipio en estudio se encuentra asentado en el terreno de la unidad sistema laguna-barrera 4 (faja de restinga), que cubre el sector de la dinámica sedimentaria eólica y de playa, como también el sector adyacente de la laguna, dominado por la dinámica de los sedimentos lacustres.

Posteriormente se identificaron unidades y elementos geomorfológicos a través de sensores remotos, datos que fueron validados en terreno. Para ello se utilizó el MANUAL TÉCNICO DE GEOMORFOLOGÍA (2009) del INSTITUTO BRASILEÑO DE GEOGRAFÍA Y ESTADÍSTICA (IBGE), junto con los trabajos ya realizados en las proximidades de la zona del proyecto.

Según el Manual Técnico de Geomorfología, es posible identificar una facie tipo planicie lacustre situada en la orilla de la Lagoa do Sombrío. Se trata de un área plana, que es resultado de los procesos formadores de cuerpos lacustres asociados a las barreras costeras. Está bordeada por una cresta que rodea prácticamente todo su margen.

Otra unidad geomorfológica identificada es la terraza lacustre, que también se encuentra en las proximidades de la Lagoa do Sombrío y que se extiende hasta las orillas del río Mampituba. Esta característica se debe a la elevación del nivel de la laguna asociada a la máxima elevación del nivel del mar durante el Holoceno, cuando había alcanzado su nivel más alto, cerca de 4 m.s.n.m (TOMAZELLI \& VILLWOCK 1995).

Al Este de la Lagoa do Sombrío se identificó una unidad geomorfológica en forma de paleo campos de dunas costeras extendidas de forma rectilínea en sentido de la orientación de la laguna. También de acuerdo con SILVA (2011) es posible observar, en dirección de la Laguna do Sombrío hasta la costa, cordones litorales que limitan con los campos de dunas regresivos actuales y paleocanales del río Mampituba, ubicados en casi toda el área de los cordones litorales. El campo de dunas regresivo actual, situado junto a la playa, es una unidad geomorfológica que obedece al balance de sedimentos transportados por la deriva litoral hacia el SW-NE.

\section{RESULTADOS}

Los antecedentes bibliográficos y el análisis de la información obtenida en los trabajos de campo, tanto como en el laboratorio SIG, han contribuido para una mejor comprensión y caracterización del municipio de Passo de Torres - SC y del área de la obra en análisis ambiental. Se generó una carta-imagen de todo el condado municipal a escala 1:50.000 y un mapa específico de la zona de pesca terminal a escala 1:2.000.

Fue posible identificar seis unidades geomorfológicas (Fig. 2): planicie lacustre, situada en los alrededores de la Lagoa do Sombrío; terraza lacustre, situada en las proximidades de la planicie lacustre hasta la orilla del río Mampituba; paleo campo de dunas, al este de la Lagoa do Sombrío; cordones litorales entre el paleo campo de dunas y el campo de dunas regresivas; paleo canal del rio Mampituba, en prácticamente toda la zona de los cordones litorales como también en algunos sectores en la zona de la terraza lacustre, y finalmente, el campo de dunas regresivo actual junto a la playa. 


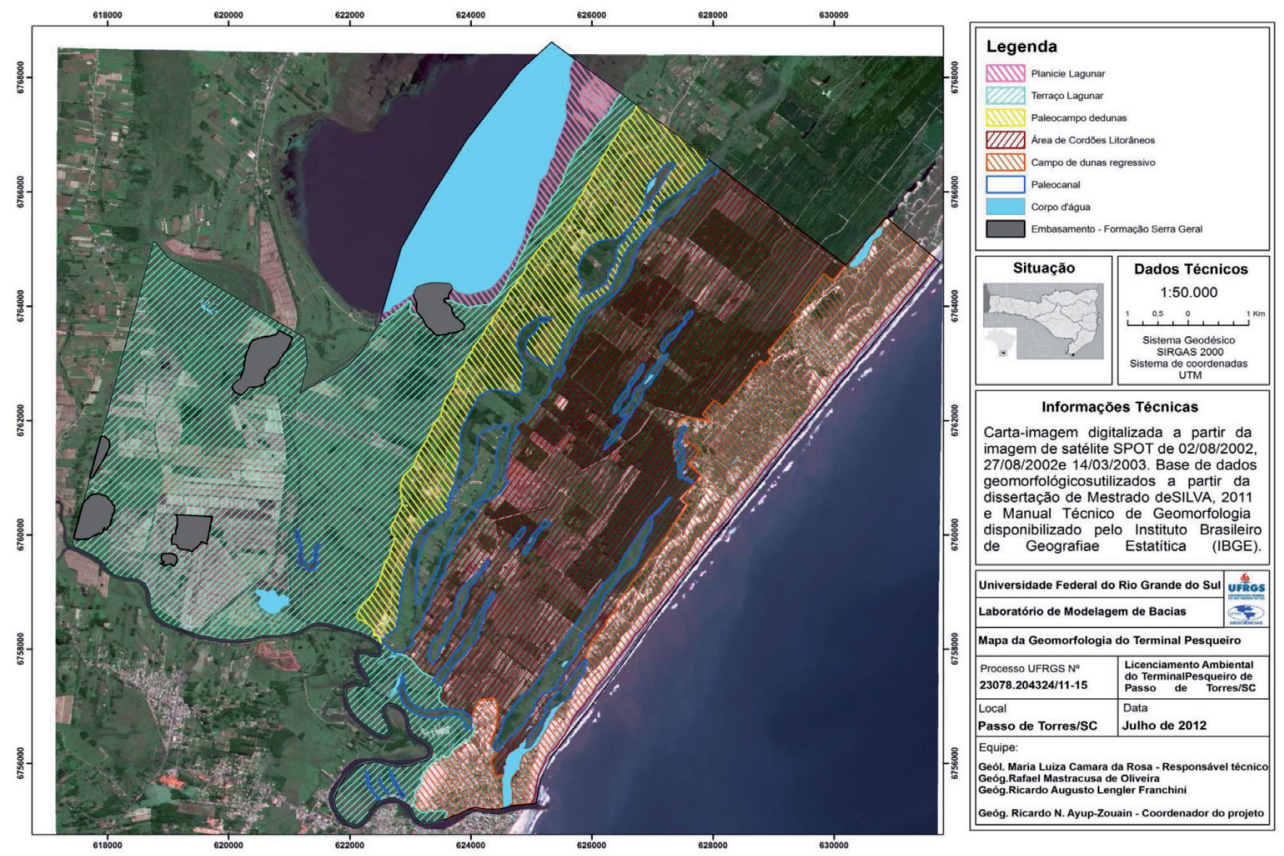

Fig. 2. Carta-imagen de la geomorfología del municipio Passo de Torres, Santa Catarina, Brasil.

El área de estudio se encuentra en el área de holocena, y también cercano a algunos la unidad geomorfológica terraza lacustre, paleocanales del río Mampituba, como se con una pequeña porción en la unidad destaca en la figura 3.

campo de dunas regresivas de la barrera

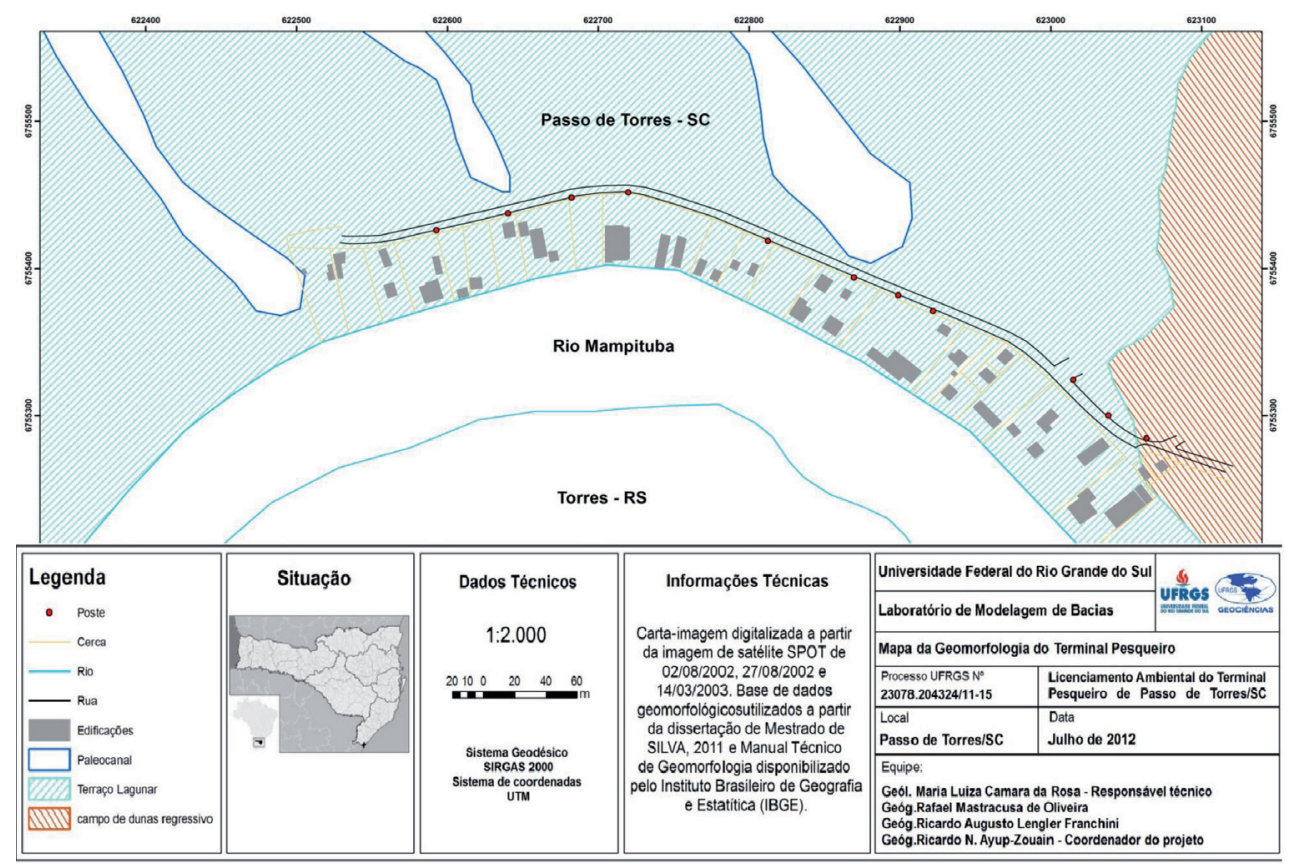

Fig. 3. Unidades geomorfológicas del área del terminal pesquero de Passo de Torres - SC, Brasil. 
Se identificaron formas $y$ estructuras residuales del basamento de la Formación Serra Geral en el borde de la Lagoa do Sombrío y cerca de la orilla del río Mampituba, que se caracterizan por la presencia de bloques de rocas basálticas intercaladas con areniscas de grano medio y fino. En el extremo oeste de la ciudad hay un afloramiento de turbas holocénicas, compuesto por sedimentos finos (limo y arcilla) en una mezcla heterogénea de arena fina. En la franja costera se han identificado depósitos de playas y eólicos recientes del Holoceno, compuestos por arenas de cuarzo medianas y finas, en constante reelaboración por el viento y el oleaje. Este sector se caracteriza morfológicamente por estar protegido de la dinámica costera y oceánica, y se asocia a la dinámica de los ambientes de agua dulce. A lo largo de la orilla del río Mampituba, en el interior del municipio, se identifican depósitos fluviales y lacustres del Holoceno, compuestos por arenas de tamaño mediano, fino y muy fino, como resultado de la re-elaboración de los sedimentos de la planicie lagunar del sistema holocénico.

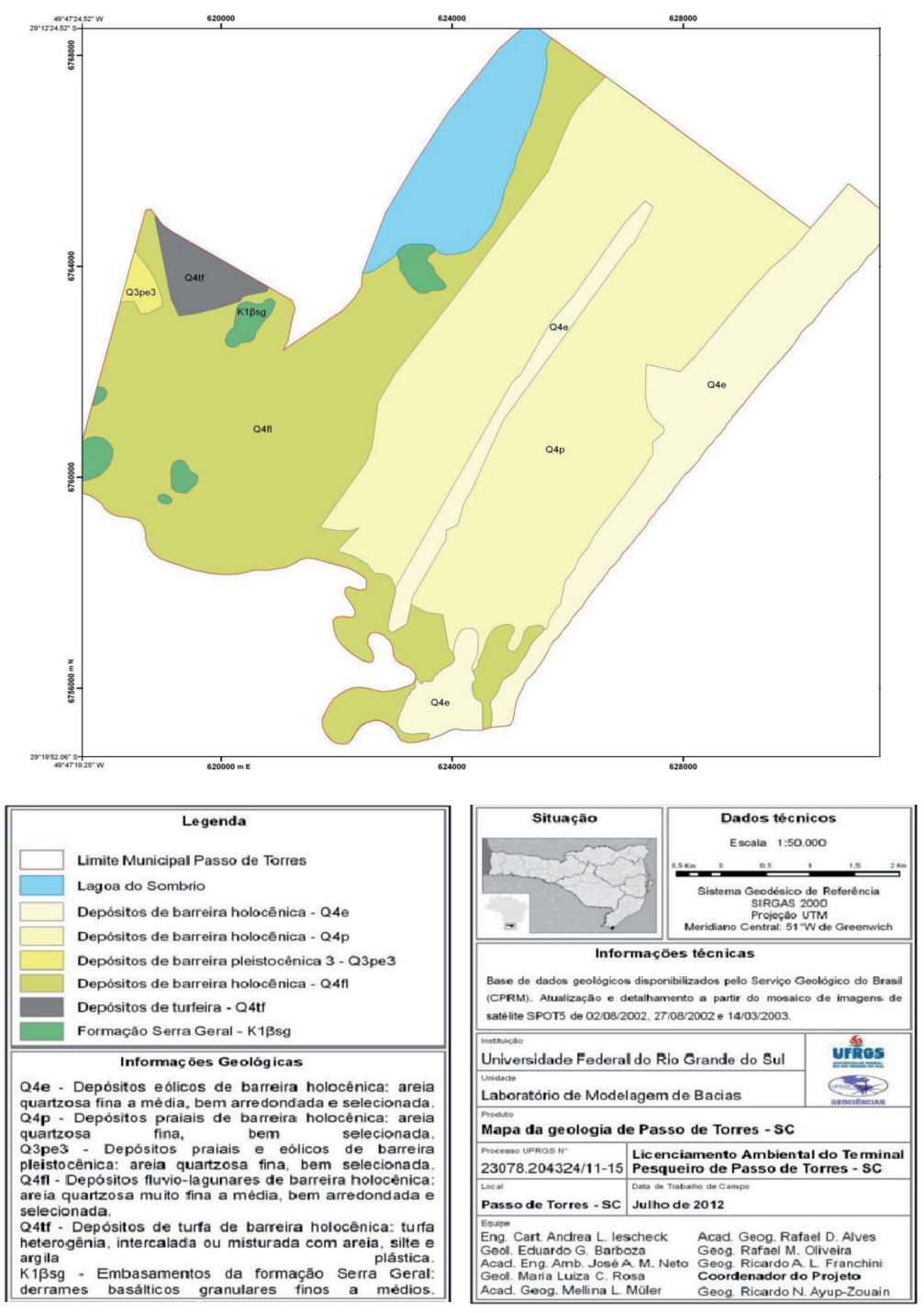

Fig. 4. Mapa geológico del municipio de Passo de Torres. 
El terminal pesquero a ser evaluado ambientalmente está situado en terrenos correspondientes a depósitos fluviolacustres del sistema laguna-barrera IV
(Holoceno), siendo este sector sometido a la re-elaboración de los sedimentos lacustres a través de la dinámica del río (Fig. 5), junto a los depósitos eólicos del sector NE.
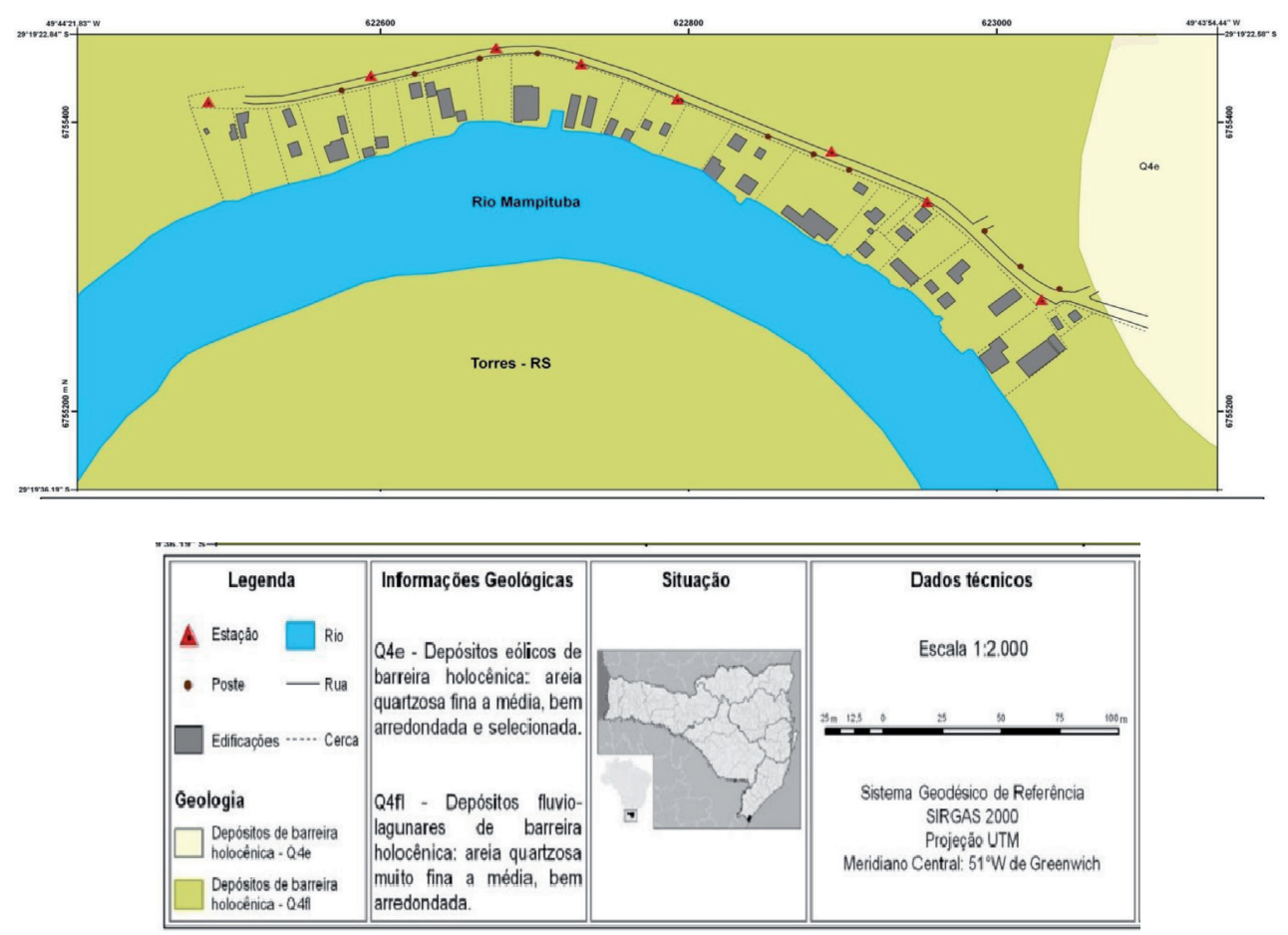

\begin{tabular}{|c|c|c|c|}
\hline \multirow[t]{2}{*}{ Informaçōes técnicas } & \multicolumn{2}{|c|}{ Universidade Federal do Rio Grande do Sul } & \multirow{2}{*}{ UFF' } \\
\hline & \multicolumn{2}{|c|}{ Laboratório de Modelagem de Bacias } & \\
\hline \multirow{2}{*}{$\begin{array}{l}\text { Base de dados geológicos } \\
\text { disponibilizados pelo Serviço }\end{array}$} & \multicolumn{3}{|c|}{ Mapa geológico do empreendimento Terminal Pesqueiro } \\
\hline & $\begin{array}{l}\text { Processo UFROS N" } \\
23078.204324 / 11-15\end{array}$ & \multicolumn{2}{|c|}{$\begin{array}{l}\text { Licenciamento Ambiental do Terminal } \\
\text { Pesqueiro de Passo de Torres - SC }\end{array}$} \\
\hline \multirow{2}{*}{$\begin{array}{l}\text { Geologico do Brasil (CPRM). } \\
\text { Atualizaçăo e detalhamento a } \\
\text { partir do mosaico de imagens } \\
\text { de satélite SPOT5 de } \\
\text { 02/08/2002, 27/08/2002 e } \\
\text { 14/03/2003. }\end{array}$} & $\begin{array}{l}\text { local } \\
\text { Passo de Torres - SC }\end{array}$ & \multicolumn{2}{|c|}{ Outubro de 2012} \\
\hline & $\begin{array}{l}\text { Equipe } \\
\text { Eng. Cart. Andrea L. lescheck } \\
\text { Geól. Eduardo G. Barboza } \\
\text { Acad. Eng. Amb. José A. M. N. } \\
\text { Geól. Maria Luiza C. da Rosa } \\
\text { Acad. Geog. Mellina L. Müller }\end{array}$ & \multicolumn{2}{|c|}{$\begin{array}{l}\text { Acad. Geog. Rafael D. Alves } \\
\text { Geóg. Rafael M. de Oliveira } \\
\text { Geóg. Ricardo A. L. Franchini } \\
\text { Eng. Cart. Ronaldo S. Rocha } \\
\text { Coordenador do projeto } \\
\text { Geóg. Ricardo N. Ayup-Zouain }\end{array}$} \\
\hline
\end{tabular}

Fig. 5. Mapa geológico del área del terminal pesquero de Passo de Torres.

\section{CONCLUSIONES}

Con el conocimiento de la dinámica del río Mampituba junto a los estudios realizados anteriormente acerca de las características locales asociadas a la geología y la geomorfología, se obtuvo una caracterización más precisa de la región, siendo posible realizar una descripción detallada de los procesos morfo esculturales y morfo estructurales ocurridos a lo largo del tiempo geológico, especialmente durante el Cuaternario, cuando se generaron las principales estructuras y facies presentes en el área de estudio. 
Con la ayuda de herramientas de sensores remotos y SIG, se pudo realizar el mapeo con el más alto nivel de detalle, siendo posible identificar las principales unidades geológicas y geomorfológicas, a diferentes escalas.

La realización de este estudio permitió aportar los antecedentes necesarios para la evaluación ambiental de la obra Terminal Pesquero Público de Passo de Torres - SC, desde el punto de vista de los antecedentes técnicos de geología y geomorfología pertinentes para la toma de decisiones de la autoridad competente.

\section{REFERENCIAS}

ANGULO, R.J., DILLENBURG, S.R., LESSA, G.C., SUGUIO, K. \& J.A.VILLWOCK, 2005. Geologia e Geomorfologia de Regiões Costeiras. Quaternário do Brasil. Editora Holos: 94 107.

COMPANHIA DE PESQUISA DE RECURSOS MINERAIS (CPRM), 2009. Serviço Geológico do Brasil. http://www. cprm.gov.br/

DIEHL, F.L. \& N.O. HORN, F., 1996. Compartimentação GeológicoGeomorfológica da Zona Litorânea e Planície Costeira do Estado de Santa Catarina. Notas Técnicas, 9: 39-50.

DILLENBURG, S.R., ROY, P.S., COWELL, P.J. \& L.J. TOMAZELLI, 2000. Influence of antecedent topography on coastal evolution as tested by the shoreface translation barrier model (STM). Journal of Coastal Research, 16: 71-81.

MANUAL TÉCNICO DE GEOMORFOLOGÍA, 2009. Instituto Brasileiro de Geografia e Estatística (IBGE). http://www.ibge.gov.br/home/geociencias/ recursosnaturais/geomorfologia/manual geomorfologia.shtm
MARTINHO, C. T., GIANNINI, P.C.F. \& A.O. SAWAKUCHI, 2006. Morphological and Depositional Facies of Transgressive Dunefields in the Imbituba-Jaguaruna Region, Santa Catarina State, Southern Brazil. Journal of Coastal Research, SI 39: 673-677.

SILVA, A.B., 2009. Mapeamento e Caracterização dos Depósitos em Subsuperfície do Setor Meridional da Planície Costeira de Santa Catarina. Trabalho de Conclusão de Curso de Graduação em Geologia, Universidade Federal do Rio Grande do Sul, Inédito.

SILVA, A.B., 2011. Análise Estratigráfica da Barreira Transgressiva Holocênica na Região da Lagoa do Sombrio - SC. UFRGS. Dissertação de Mestrado, Universidade Federal do Rio Grande do Sul, Inédito.

SUGUIO, K. \& L.R. MARTIN, 1978. Formações Quaternárias Marinhas do Litoral Paulista e Sul Fluminense. In: International Symposium on Coastal Evolution in the Quaternary, 1: 1-54.

VILLWOCK, J. A., TOMAZELLI, L.J., LOSS, E.L., DEHNHARDT, E.A., HORN, P.N.O., BACHI, F.A. \& B.A. DEHNHARDT, 1986. Geology of the Rio Grande do Sul Coastal Province. In: J. Rebassa (ed) Quaternary of South America and Antarctic Peninsula, Rotterdam, Balkema, 4: 79-97.

VILLWOCK, J. A. \& L.J. TOMAZELLI, 1995. Geologia Costeira do Rio Grande do Sul. Notas Técnicas 8: 1-45. 